\title{
INTEGRATED PAPER
}

\section{Ionic Probe Attachment Ionization Mass Spectrometry}

\author{
Fumihiro Ito, * Shin Ando, Masato Iuchi, Taki Ukari, Momoka Takasaki, \\ Tomoko Nakamura, Satoko Yorita, and Kentaro Yamaguchi*
}

\author{
Faculty of Pharmaceutical Sciences at Kagawa Campus, Tokushima Bunri University, Sanuki, KAGAWA, JAPAN
}

\begin{abstract}
We have developed a new ionization method that uses metal-complex-based ionization probes containing the 2,6-bis (oxazolinyl) pyridine (pybox) ligand, NHS-TMpybox, Mal-TMpybox, BrAc-TMpybox, oxime-TMpybox, and Sar-TMpybox. NHSTMpybox, Mal-TMpybox, BrAc-TMpybox, and oxime-TMpybox were reacted selectively with the functional groups of biomolecules, whereas Sar-TMpybox was reacted with carbon clusters. These were able to obtain multiply charged ions of target molecules. This method was proven to effectively ionize large complex molecules, including biomolecules and various supramolecules, as well as carbon clusters, such as fullerenes. Moreover, isotope-labeled pybox-La complexes were used to clearly detect isotopic labeling shifts. Their applications to multiply charged ionization, including isotope labeling of biomolecules and carbon clusters using cold-spray ionization mass spectrometry (CSI-MS), are shown.

DOI: $10.5702 /$ massspec.11-32
\end{abstract}

(Received November 2, 2011; Accepted December 6, 2011)

\section{Introduction}

Mass spectrometry (MS) is an essential tool for the characterization of various compounds as it features high sensitivity and reliability for the detection of chemical, pharmaceutical, biological, and environmental substances. The continuous development of the soft ionization technique is thought to have sparked the advancement of MS. Since electron ionization (EI), the first practical ionization method used in chemistry, was coined, remarkable progress has been made in this area. Recent soft ionization technique has made it possible to analyze such biomacromolecules as proteins. ${ }^{1)}$ The technique is based on electrospray ionization (ESI) ${ }^{2)}$ and matrix-assisted laser desorption ionization (MALDI). ${ }^{3)}$ During analysis under soft ionization conditions, the higher order structure of a biomacromolecule is preserved. Therefore, the elucidation of primary structures as well as higher order structures ${ }^{4)}$ and their dynamics has become possible, and post-translational modification analysis has become a reality.

However, problems that hinder the reliable and reproducible ionization of complex large biomolecules by these methods still remain because of the oft-observed ambiguous protonation during ESI-MS analysis. The protonation seems to occur less often in the case of cold-spray ionization (CSI), a variant of the ESI method operating under low temperature to ionize labile organic species. ${ }^{5)}$ Therefore, an effective adjustable-charge-state ionization technique ${ }^{6)}$ is required for these molecules. We have recently developed a new method called "ionic probe attachment ionization".7),8) We have designed ionic probes "TMpybox series" that can donate multiple charges contained in the metal charged site of the probe molecule to the target compound. The probe comprises three

* Correspondence to: Fumihiro Iто, Faculty of Pharmaceutical Sciences at Kagawa Campus, Tokushima Bunri University, 1314-1 Shido, Sanuki, KAGAWA 769-2193, JAPAN, e-mail: h-itoh@kph. bunri-u.ac.jp; Kentaro YAMAGUCHI, e-mail: Yamaguchi@kph. bunri-u.ac.jp

Published online December 12, 2011 functional parts: a charged site, a linker, and an anchoring site (Fig. 1). Pybox-La complex, which enables complex formation under mild conditions, is used as the charged site. An alkyl chain is used as the linker. Five anchoring sites that enable selective reaction with various target compounds were developed: $N$-hydroxysuccinimide (NHS) for amino groups, maleimide (Mal) for thiols, $\alpha$-bromoacetate (BrAc) for carboxylic acids, hydroxylamine for carbonyl groups, and sarcosinate (Sar) for carbon clusters.

Each probe is reacted selectively with the target compound by using "methods A to E" (see Experimental) to obtain the corresponding ionic species having multiple charges. The charged site is formed by the pybox-La complex through the five probes. Method A yields the ionic species after purification. On the other hand, methods B to E do not require the purification step. NHS-TMpybox, Mal-TMpybox, BrAcTMpybox, Sar-TMpybox, and oxime-TMpybox are reacted selectively with amines (methods A and B), thiols (methods $A$ and $B$ ), carboxylic acids (method C), fullerenes in the presence of benzaldehyde ${ }^{9)}$ (method D), and ketones (method E), respectively (Fig. 2).

Furthermore, isotope-labeled ionic probes have been also investigated. ${ }^{10)-12)}$ The combination of stable isotope labeling and MS using ESI and MALDI has been developed. ${ }^{13)-16)}$ This technique has made it possible to solve various problems in bioanalytical research by means of metabolic tracer experiments. Isotope labeling plays a significant role in the analysis of large complex molecules by NMR and MS. As regards pre-

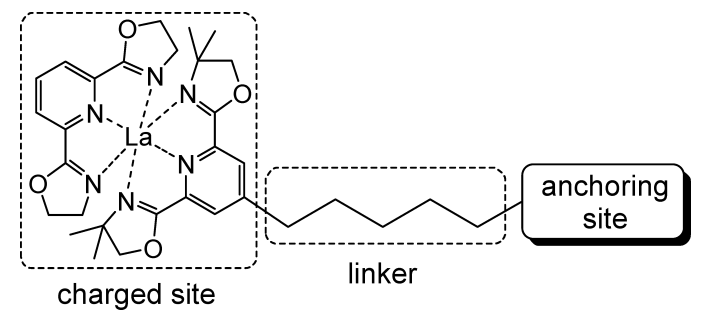

Fig. 1. Constitution of charged probes. 


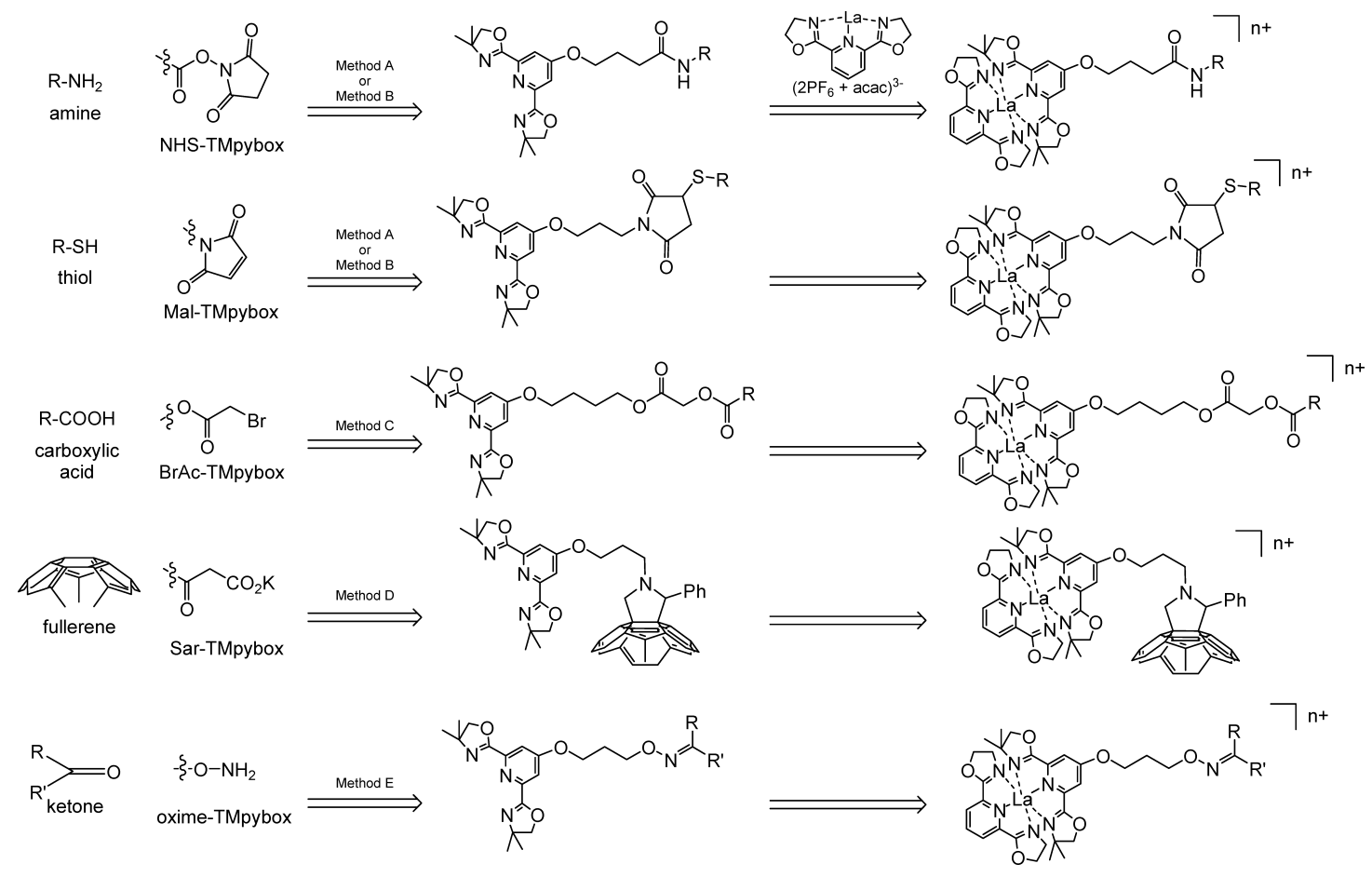

Fig. 2. Multiply charged ionic probes (TMpybox series) and multiply charged ionization.

vious studies that used isotope labeling in MS, the isotopecoded affinity tag (ICAT) ${ }^{17)}$ and the isotope tag and the isobaric tag for relative and absolute quantitation (iTRAQ) ${ }^{18)}$ have been demonstrated to be useful for proteomics MS probes that can be reacted with various functional groups to increase the relative abundance of ions formed from compounds. ${ }^{19)-27)}$

In this integrated paper, we describe the application of the charged probes and the detection of the isotopic labeling shifts for biomolecules and carbon clusters under soft ionization conditions by CSI-MS.

\section{Experimental}

CSI mass spectra were measured on a JEOL JMS-T100LC mass spectrometer equipped with a cold-spray ion source. This setup makes it possible to conduct measurements at low temperatures. Measurement conditions were as follows: sprayer temperature: -20 to $20^{\circ} \mathrm{C}$; needle voltage: $+1,500$ to $2,500 \mathrm{~V}$; ring lens voltage: +5 to $10 \mathrm{~V}$; orifice 1 voltage: +20 to $50 \mathrm{~V}$; orifice 2 voltage: +5 to $10 \mathrm{~V}$; conc. ca. $0.5 \mathrm{mM}$.

2.1 NHS-TMpybox and Mal-TMpybox (Method A: with purification)

A DMSO solution of probe (NHS-TMpybox or MalTMpybox) was added to an aqueous solution of target compound (amine or thiol) at room temperature. After the mixture was stirred at room temperature for $24 \mathrm{~h}$, it was purified by reverse-phase flash column chromatography. After the modified target compound was added to a $\mathrm{CH}_{3} \mathrm{CN}$ solution of pybox-La complex, the mixture was stirred at room temperature for $2 \mathrm{~h}$. An aliquot of the mixture was diluted with $\mathrm{CH}_{3} \mathrm{CN}$ and detected by CSI-MS.

(Method B: without purification)

A DMSO solution of probe (NHS-TMpybox or MalTMpybox) was added to an aqueous solution of target compound (amine or thiol) at room temperature. After the mixture was stirred at room temperature for $24 \mathrm{~h}$, it was frozen in vacuum. After the residue was added to a $\mathrm{CH}_{3} \mathrm{CN}$ solution of
pybox-La complex, the mixture was stirred at room temperature for $2 \mathrm{~h}$. An aliquot of the mixture was diluted with $\mathrm{CH}_{3} \mathrm{CN}$ and analyzed by CSI-MS.

\subsection{BrAC-TMpybox (Method C)}

A suspension of target carboxylic acid, sodium bicarbonate, and BrAc-TMpybox in N,N-dimethylformamide (DMF) was stirred at room temperature. Then, a DMF solution of the derivative was poured into an $\mathrm{CH}_{3} \mathrm{CN}$ solution of the pybox-La complex and mass spectrometric measurement was conducted under CSI-MS conditions.

\subsection{Sar-TMpybox (Method D)}

A suspension of Sar-TMpybox, benzaldehyde, and fullerene in toluene was refluxed for $24 \mathrm{~h}$. After the reaction mixture was filtered and toluene was removed in vacuo, the residue was washed with $\mathrm{Et}_{2} \mathrm{O}$. The suspension of fullerene derivative and pybox-La complex in $\mathrm{CH}_{3} \mathrm{CN}$ was stirred at room temperature. This solution was diluted with $\mathrm{CH}_{3} \mathrm{CN}$ and subjected to CSI-MS measurement.
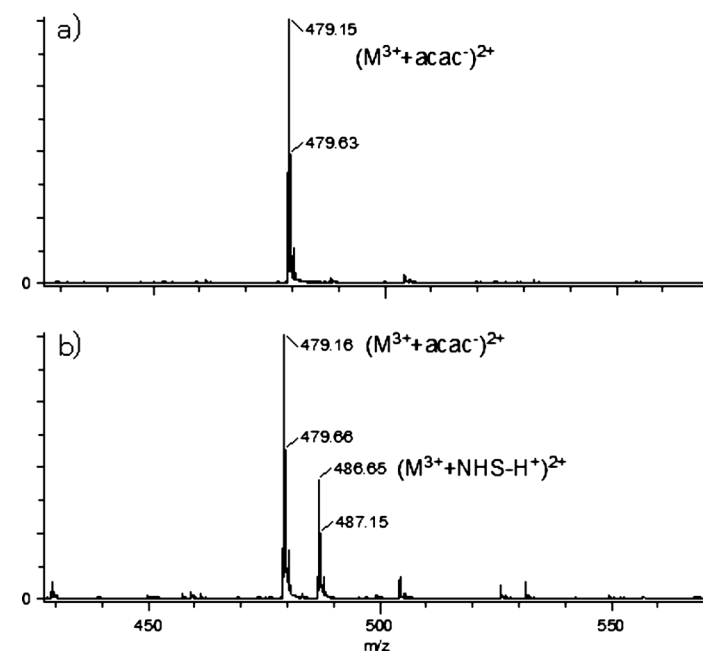

Fig. 3. CSI mass spectra of K: a) method A and b) method B. 

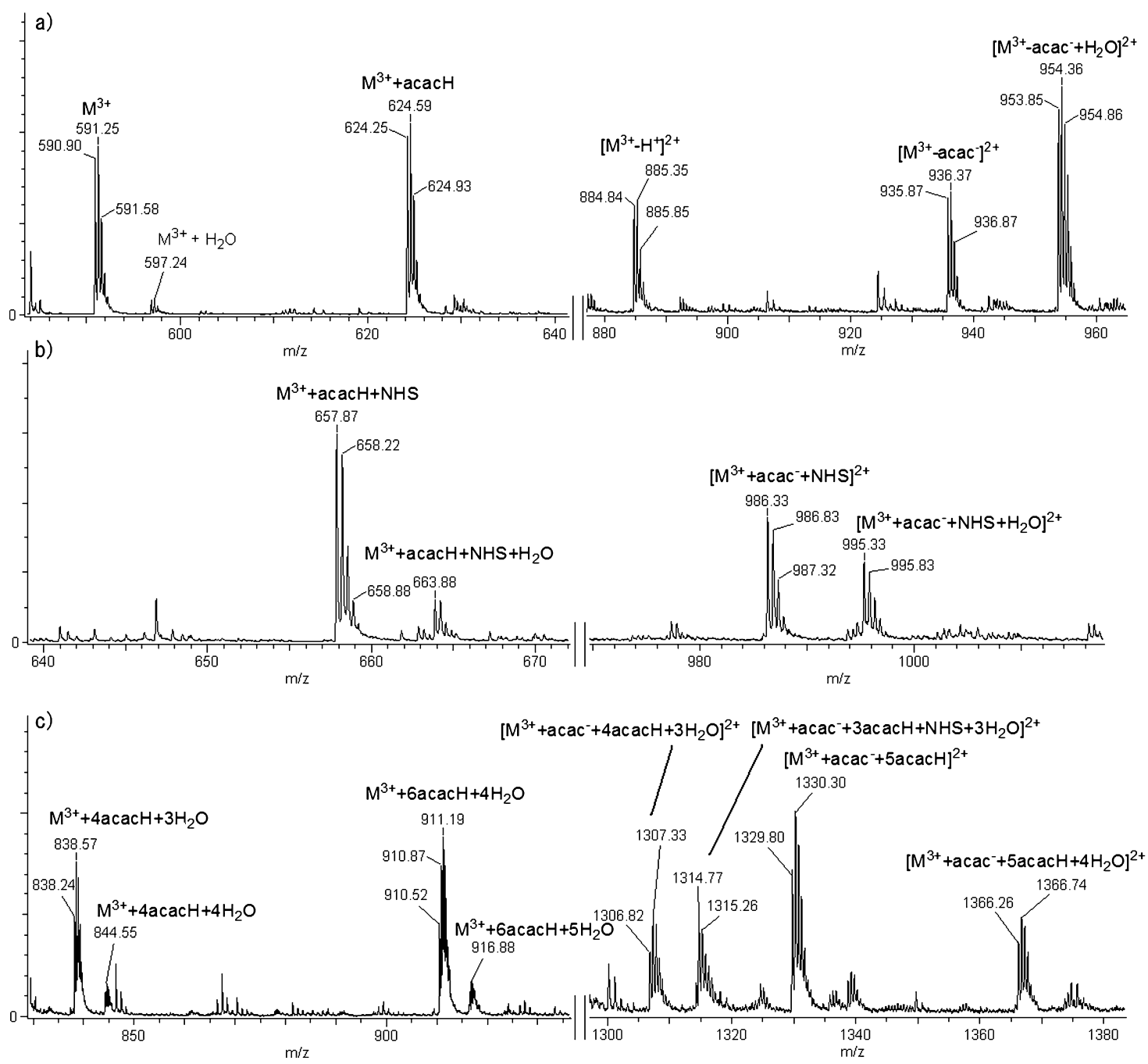

Fig. 4. CSI mass spectra of a) BK, b) AT-II, and c) SP.
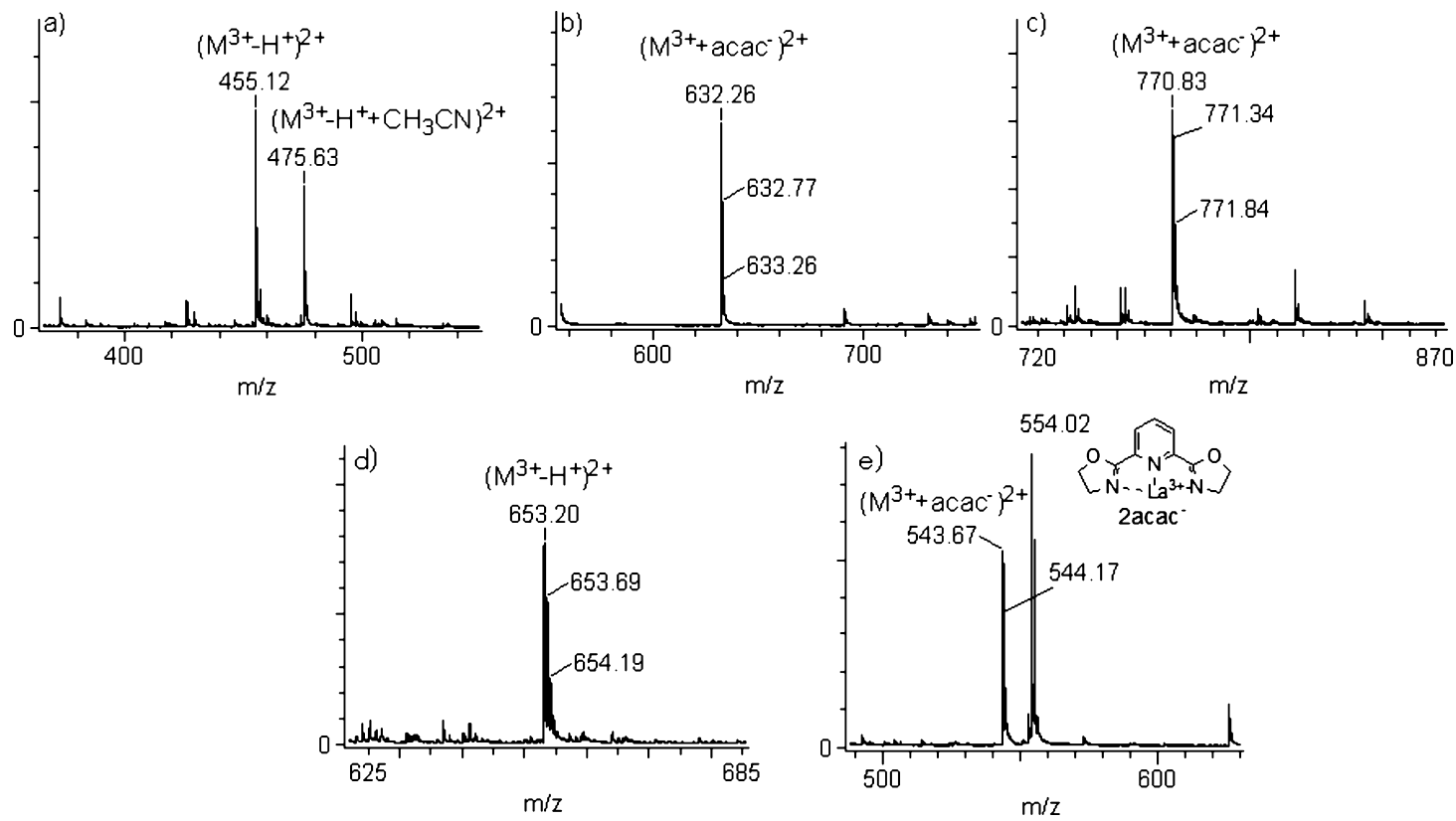

Fig. 5. CSI mass spectra of a) DHBA, b) CA, c) PA, d) TTCTT, and e) TS. 


\subsection{Oxime-TMpybox (Method E)}

After a pyridine solution of the target carbonyl compound and oxime-TMpybox was stirred at $80^{\circ} \mathrm{C}$, the pyridine solution was added to an $\mathrm{CH}_{3} \mathrm{CN}$ solution of pybox-La complex and mass spectrometric measurement was conducted under CSI-MS conditions.

\section{Results and Discussion}

\subsection{Ionic probe attachment ionization MS}

At first, two methods (methods A and B) to introduce NHS-TMpybox to lysine (K) are shown in Fig. 3. Modified K via method A exhibited a doubly charged ion peak $\left[\mathrm{M}^{3+}+\right.$
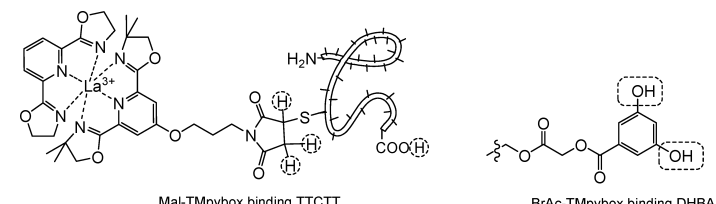

Fig. 6.
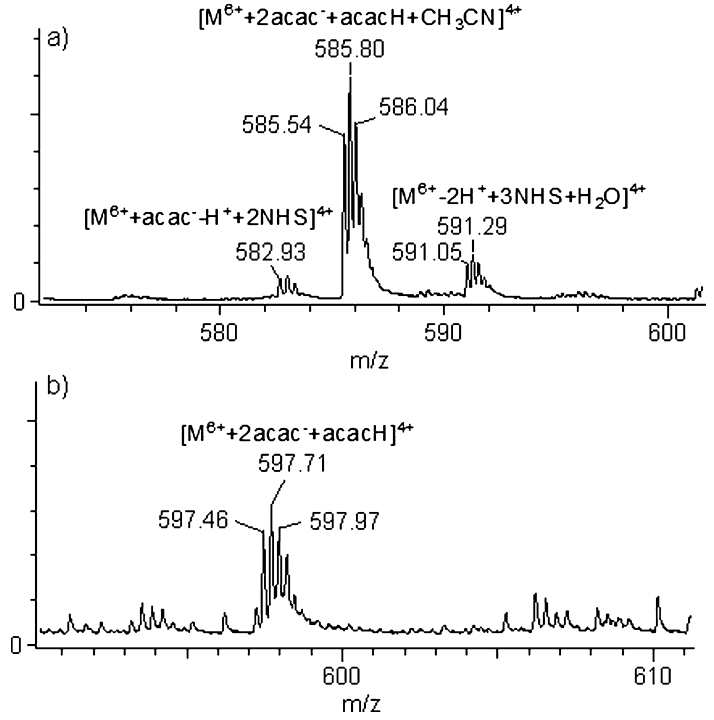

Fig. 7. CSI mass spectra of a) KTTTK and b) CTTTC.
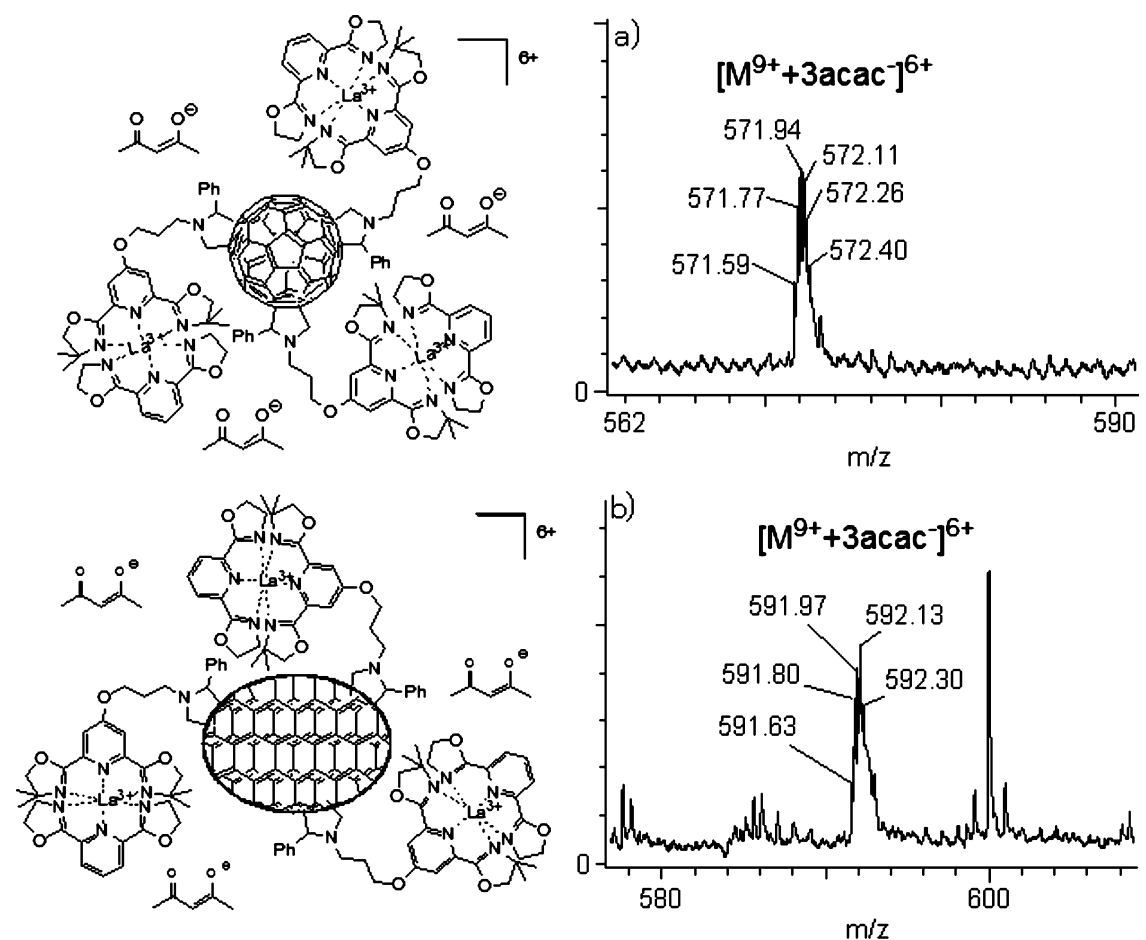

Fig. 8. CSI mass spectra of a) $\mathrm{C}_{60}$ and b) $\mathrm{C}_{70}$.

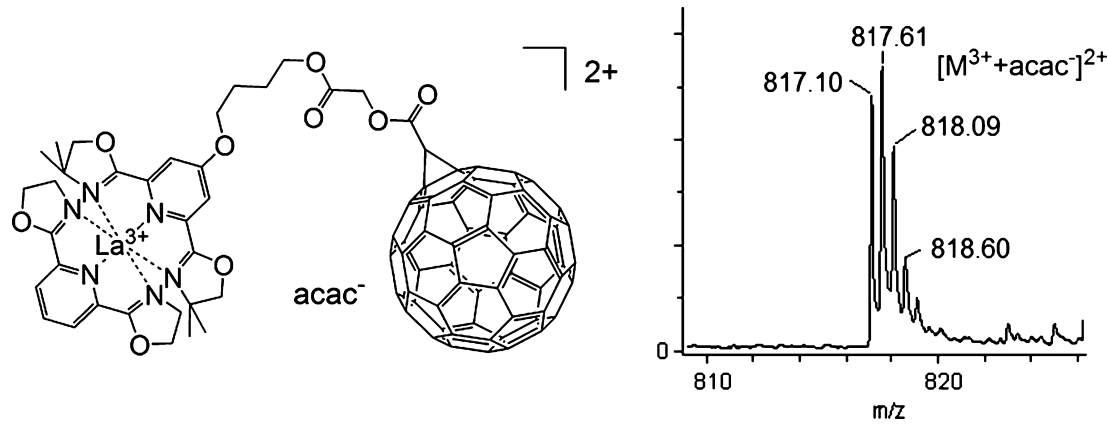

Fig. 9. CSI mass spectrum of (1,2-methano-fullerene $\left.\mathrm{C}_{60}\right)-61$ carboxylic acid with BrAc-TMpybox. 


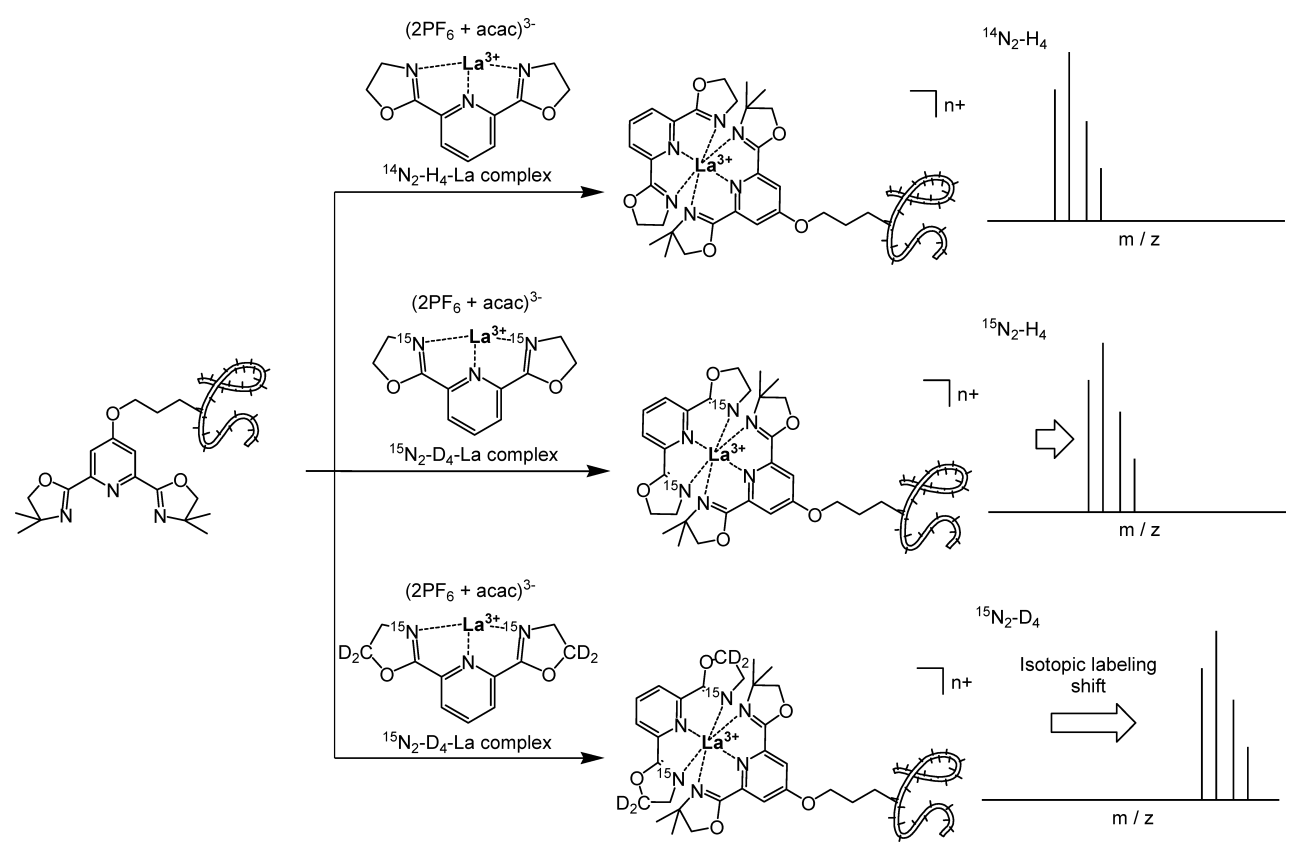

Fig. 10.

acetylacetonato $\left.\left(\mathrm{acac}^{-}\right)\right]^{2+}$ in the CSI mass spectrum (Fig. 3a). The expected triply charged ion peak was not detected because the acac ${ }^{-}$moiety derived from pybox-La complex cancelled one charge of this ion. On the other hand, in the case of method $\mathrm{B},\left[\mathrm{M}^{3+}+\mathrm{acac}^{-}\right]^{2+}$ and $\left[\mathrm{M}^{3+}+\mathrm{NHS}\right.$ $\left.-\mathrm{H}^{+}\right]^{2+}$ ion peaks were detected (Fig. 3b). NHS removed from NHS-TMpybox functioned as a counter anion in the case of method B. Although method A afforded clear ion peaks in the spectrum compared to method $B$, method $B$, which is simpler than method A, is thought to be more favorable for the analysis of complex large biomolecules.

Next, we adopted method B using NHS-TMpybox to various peptides [bradykinin (BK), angiotensin-II (AT-II), and substance $\mathrm{P}$ (SP)] (Fig. 4). In the case of BK, triply charged ions $[\mathrm{M}]^{3+}(m / z 591),\left[\mathrm{M}+\mathrm{H}_{2} \mathrm{O}\right]^{3+}(m / z 597)$, and $[\mathrm{M}+$ acetylacetone $(\mathrm{acacH})]^{3+}(\mathrm{m} / z 624)$, and doubly charged ions $\left[\mathrm{M}^{3+}-\mathrm{H}^{+}\right]^{2+}(\mathrm{m} / z 885),\left[\mathrm{M}^{3+}+\mathrm{acac}^{-}\right]^{2+}(\mathrm{m} / z$ 936), and $\left[\mathrm{M}^{3+}+\mathrm{acac}^{-}+2 \mathrm{H}_{2} \mathrm{O}\right]^{2+}(\mathrm{m} / z$ 954) were detected (Fig. $4 a)$. Similar to BK, in the CSI mass spectrum of AT-II, triply charged ions $[\mathrm{M}+\mathrm{acacH}+\mathrm{NHS}]^{3+}(\mathrm{m} / z$ 658) and $[\mathrm{M}+$ $\left.\mathrm{acacH}+\mathrm{NHS}+\mathrm{H}_{2} \mathrm{O}\right]^{3+}(m / z$ 995) were detected (Fig. $4 \mathrm{~b})$. Finally, in the case of SP, triply charged ions $[\mathrm{M}+4 \mathrm{acacH}$ $\left.+3 \mathrm{H}_{2} \mathrm{O}\right]^{3+}\left(\mathrm{m} / z\right.$ 838), $\left[\mathrm{M}+4 \mathrm{acacH}+4 \mathrm{H}_{2} \mathrm{O}\right]^{3+}(\mathrm{m} / z$ 844), $\left[\mathrm{M}+6 \mathrm{acacH}+4 \mathrm{H}_{2} \mathrm{O}\right]^{3+}(\mathrm{m} / z$ 911), and $[\mathrm{M}+6 \mathrm{acacH}$ $\left.+5 \mathrm{H}_{2} \mathrm{O}\right]^{3+}(\mathrm{m} / \mathrm{z} 916)$, and doubly charged ions $\left[\mathrm{M}^{3+}\right.$ $\left.+\mathrm{acac}^{-}+4 \mathrm{acacH}+3 \mathrm{H}_{2} \mathrm{O}\right]^{2+}(m / z 1307),\left[\mathrm{M}^{3+}+\mathrm{acac}^{-}\right.$ $\left.+3 \mathrm{acacH}+\mathrm{NHS}+3 \mathrm{H}_{2} \mathrm{O}\right]^{2+}\left(\mathrm{m} / z\right.$ 1315), $\left[\mathrm{M}^{3+}+\mathrm{acac}^{-}\right.$ $+5 \mathrm{acacH}]^{2+}(\mathrm{m} / z 1330)$, and $\left[\mathrm{M}^{3+}+\mathrm{acac}^{-}+5 \mathrm{acacH}\right.$ $\left.+4 \mathrm{H}_{2} \mathrm{O}\right]^{2+}(\mathrm{m} / z$ 1366) were detected (Fig. 4c).

Next, the results of multiply charged ionization of target compounds [3,5-dihydroxycarboxylic acid (DHBA), cholic acid (CA), pepstatin A (PA), TTCTT (custompeptide), and testosterone (TS)] with other MS probes (BrAc-TMpybox, Mal-TMpybox, and oxime-TMpybox) are shown in Fig. 5. In the case of BrAc-TMpybox, doubly charged ions $\left[\mathrm{M}^{3+}\right.$ $\left.-\mathrm{H}^{+}\right]^{2+}\left(\mathrm{m} / z\right.$ 455) and $\left[\mathrm{M}^{3+}-\mathrm{H}^{+}+\mathrm{CH}_{3} \mathrm{CN}\right]^{2+}(\mathrm{m} / z$ 476) in DHBA (Fig. 5a), and $\left[\mathrm{M}^{3+}+\mathrm{acac}^{-}\right]^{2+}(\mathrm{m} / z 632$ and 770, respectively) in CA and PA, were detected (Fig. 5b and 5c). Clearly, BrAc-TMpybox reacted with the carboxyl group,
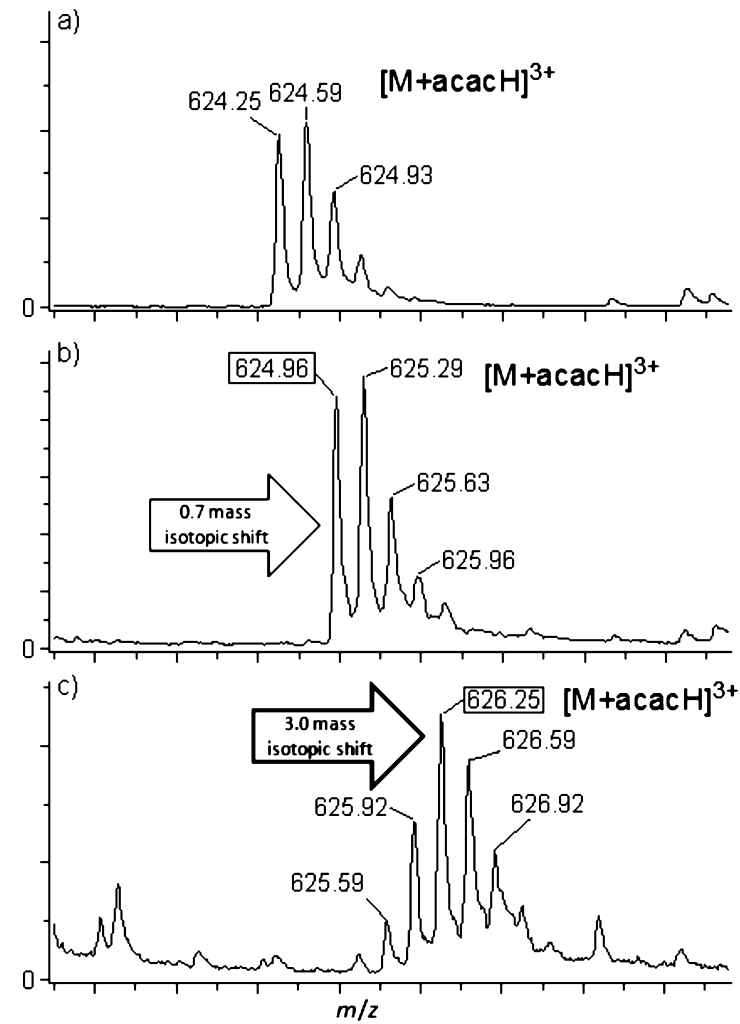

Fig. 11. CSI mass spectra of a) ${ }^{14} \mathrm{~N}_{2}-\mathrm{H}_{4}-\mathrm{BK}$, b) ${ }^{15} \mathrm{~N}_{2}-\mathrm{H}_{4}-\mathrm{BK}$, and c) ${ }^{15} \mathrm{~N}_{2}-\mathrm{D}_{4}-\mathrm{BK}$.

whereas other aliphatic and aromatic hydroxyl groups in each compound, which are able to react with BrAc-TMpybox under basic conditions, were inactive even in the presence of an excess amount of this reagent by method $\mathrm{C}$. On the other hand, in the case of TTCTT using Mal-TMpybox, similar to DHBA, doubly charged ion $\left[\mathrm{M}^{3+}-\mathrm{H}^{+}\right]^{2+}(\mathrm{m} / z$ 653) was detected (Fig. 5d). A doubly charged ion $\left[\mathrm{M}+\mathrm{acac}^{-}\right]^{2+}$ $(\mathrm{m} / z$ 544) was detected in TS using oxime-TMpybox and a single ion peak of pybox-La complex $(m / z 554)$ was detected 


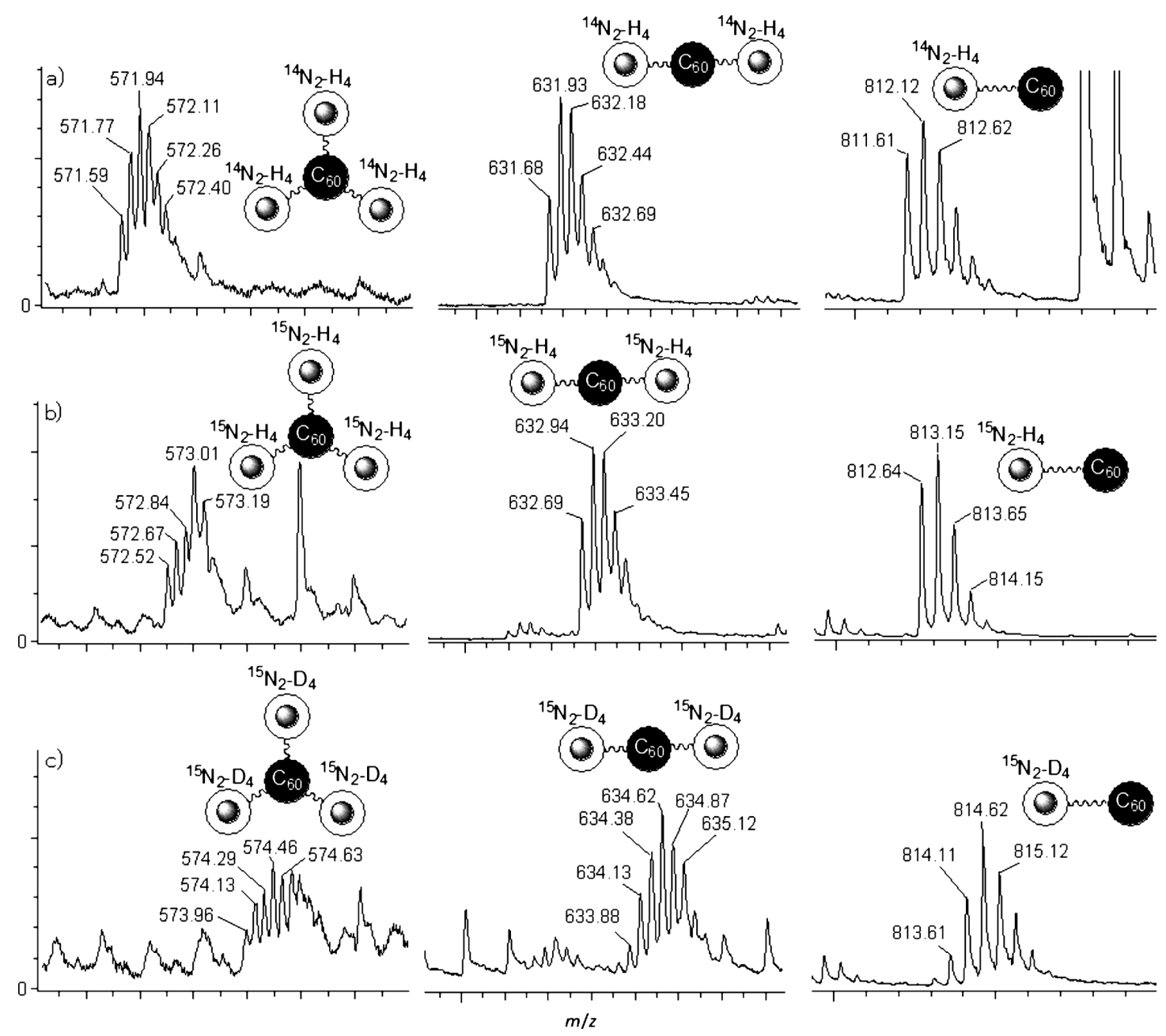

Fig. 12. CSI mass spectra of a) ${ }^{14} \mathrm{~N}_{2}-\mathrm{H}_{4}-\mathrm{C}_{60}$, b) ${ }^{15} \mathrm{~N}_{2}-\mathrm{H}_{4}-\mathrm{C}_{60}$, and c) ${ }^{15} \mathrm{~N}_{2}-\mathrm{D}_{4}-\mathrm{C}_{60}$.

as well (Fig. 5e). The deprotonation behavior as well as the presence or absence of $\mathrm{acac}^{-}$as counter anion is strongly related to the acidity. As the maleimide group in Mal-TMpybox and the aromatic hydroxyl group in DHBA exhibited weak acidity, deprotonation took place in those compounds (Fig. 6).

In addition, we introduced multiply charged probes (NHSTMpybox and Mal-TMpybox) to target peptides (KTTTK and CTTTC) (Fig. 7). In the case of KTTTK using NHSTMpybox, quadruply charged ions $\left[\mathrm{M}^{6+}+\mathrm{acac}^{-}-\mathrm{H}^{+}\right.$ $+2 \mathrm{NHS}]^{4+}(m / z 583),\left[\mathrm{M}^{6+}+2 \mathrm{acac}^{-}+\mathrm{acacH}+\right.$ $\left.\mathrm{CH}_{3} \mathrm{CN}\right]^{4+}(m / z 586)$, and $\left[\mathrm{M}^{6+}-2 \mathrm{H}^{+}+3 \mathrm{NHS}+\mathrm{H}_{2} \mathrm{O}\right]^{4+}$ $(\mathrm{m} / z$ 591) were detected (Fig. 7a). Similar to KTTTK, quadruply charged ion $\left[\mathrm{M}^{6+}+2 \mathrm{acac}^{-}+\mathrm{acacH}\right]^{4+}(\mathrm{m} / \mathrm{z} 597)$ was also detected in CTTTC using Mal-TMpybox (Fig. 7b).

The results of multiply charged ionization of carbon clusters (fullerenes $\mathrm{C}_{60}$ and $\mathrm{C}_{70}$ ) with Sar-TMpybox are shown in Fig. 8. Fullerene $\mathrm{C}_{60}$ was reacted with one to six probes and $\left[\mathrm{M}^{9+}\right.$ $\left.+3 \mathrm{acac}^{-}\right]^{6+}(\mathrm{m} / \mathrm{z} 572)$ was detected from the formation of charged site coupled with pybox-La complex (Fig. 8a). On the other hand, fullerene $C_{70}$ was reacted with one to five probes and similar to $\mathrm{C}_{60}$, multiply charged ion $\left[\mathrm{M}^{9+}\right.$ $\left.+3 \mathrm{acac}^{-}\right]^{6+}(\mathrm{m} / \mathrm{z} 592)$ was detected by the same method as that applied to $\mathrm{C}_{60}$ (Fig. 8b).

Finally, this method was adopted to (1,2-methano-fullerene $\mathrm{C}_{60}$ ) -61 carboxylic acid as an example of a substituted $\mathrm{C}_{60}$. As complex fullerene derivatives possessing various functional groups have been prepared only quite recently, ${ }^{28)-33)}$ we examined the ionic probe attachment ionization of commercially available fullerene derivatives. In the case of fullerene having a carboxyl group as the functional group, BrAc-TMpybox was attached to the carboxyl group with method C. $\mathrm{C}_{60}$ derivative was detected as a doubly charged ion $\left[\mathrm{M}^{3+}+\mathrm{acac}^{-}\right]^{2+}$ $(m / z 817)$ (Fig. 9).

3.2 Isotope-labeled probe attachment mass spectrometry

Next, we describe the isotope-labeled multiply charged ionization of target compounds ( $\mathrm{BK}$ and fullerene $\mathrm{C}_{60}$ ) with NHS-TMpybox, Sar-TMpybox, and isotope-labeled pybox-La complexes $\left[{ }^{15} \mathrm{~N}_{2}-\mathrm{H}_{4}\right.$-La and ${ }^{15} \mathrm{~N}_{2}-\mathrm{D}_{4}$-La complexes (Fig. 10)] (Figs. 11 and 12).

In the case of ${ }^{14} \mathrm{~N}_{2}-\mathrm{H}_{4}$-BK and ${ }^{15} \mathrm{~N}_{2}-\mathrm{H}_{4}$-BK, which were prepared by method $\mathrm{B}$ using NHS-TMpybox, triply charged ions of $[\mathrm{M}+\mathrm{acacH}]^{3+}(\mathrm{m} / z 624$ and 625) (Fig. 11a and 11b, respectively) were observed in the CSI mass spectra. The isotopic shift of ca. $m / z 0.7(2 / 3)$, which corresponded to the increase in mass induced by two ${ }^{15} \mathrm{~N}$ atoms on an ion with three charges, was detected. On the other hand, in the CSI mass spectrum of ${ }^{15} \mathrm{~N}_{2}-\mathrm{D}_{4}$-BK, triply charged ion of $[\mathrm{M}$ $+\mathrm{acacH}]^{3+}(\mathrm{m} / z$ 626) (Fig. 11c) was clearly observed. The isotopic shift of ca. $m / z 2.0(6 / 3)$, which corresponded to the increase in mass induced by two ${ }^{15} \mathrm{~N}$ and four $\mathrm{D}$ atoms on an ion with three charges, was detected. The partially isotope-labeled ions of $m / z 625.6{ }^{15} \mathrm{~N}_{2}-\mathrm{H}_{2}-\mathrm{D}_{2}-\mathrm{BK}$ and $m / z 625.9{ }^{15} \mathrm{~N}_{2}$ - 
Table 1. Mass-to-Charge Ratio of Isotope-Labeled $\mathrm{C}_{60}$

\begin{tabular}{cccc}
\hline $\begin{array}{c}\text { Number of probes attached } \\
\text { (charge state) }\end{array}$ & ${ }^{14} \mathrm{~N}_{2}-\mathrm{H}_{4}$ & ${ }^{15} \mathrm{~N}_{2}-\mathrm{H}_{4}$ & ${ }^{15} \mathrm{~N}_{2}-\mathrm{D}_{4}$ \\
\hline $1(2+)$ & 812 & 813 & 815 \\
$2(4+)$ & 632 & 633 & 635 \\
$3(6+)$ & 572 & 573 & 575 \\
\hline
\end{tabular}

Table 2. Mass-to-Charge Ratio Based on Partially Labeled Ions

\begin{tabular}{cccccc}
\hline $\begin{array}{c}\text { Number of } \\
\text { probes attached } \\
\text { (charge state) }\end{array}$ & $\mathrm{D}_{4}\left(\mathrm{H}_{0}\right)$ & $\mathrm{D}_{3}\left(\mathrm{H}_{1}\right)$ & $\mathrm{D}_{2}\left(\mathrm{H}_{2}\right)$ & $\mathrm{D}_{1}\left(\mathrm{H}_{3}\right)$ & $\mathrm{D}_{0}\left(\mathrm{H}_{4}\right)$ \\
\hline $1(2+)$ & 815.0 & 814.0 & 813.5 & - & - \\
$2(4+)$ & 635.0 & 634.4 & 634.1 & 633.9 & - \\
$3(6+)$ & 575.0 & 574.5 & 574.3 & 574.1 & 574.0 \\
\hline
\end{tabular}

\section{$\mathrm{H}_{1}-\mathrm{D}_{3}-\mathrm{BK}$ were detected.}

Finally, the CSI mass spectra of ${ }^{14} \mathrm{~N}_{2}-\mathrm{H}_{4 \mathrm{P} 14^{-}},{ }^{15} \mathrm{~N}_{2}-\mathrm{H}_{4}$, and ${ }^{15} \mathrm{~N}_{2}-\mathrm{D}_{4}-\mathrm{C}_{60}$, which were prepared by method D using SarTMpybox, are shown in Fig. 12. In the case of ${ }^{14} \mathrm{~N}_{2}-\mathrm{H}_{4}-\mathrm{La}$, multiply charged ions of $\left[\left({ }^{14} \mathrm{~N}_{2}-\mathrm{H}_{4}-\mathrm{La}\right)^{3+}-\mathrm{C}_{60}+\mathrm{acac}^{-}\right]^{2+}$ $\left(\mathrm{m} / z\right.$ 812), $\left\{2\left[\left({ }^{14} \mathrm{~N}_{2}-\mathrm{H}_{4}-\mathrm{La}\right)^{3+}\right]-\mathrm{C}_{60}+2 \mathrm{acac}^{-}\right\}^{4+}(\mathrm{m} / z$ 632), and $\left\{3\left[\left({ }^{14} \mathrm{~N}_{2}-\mathrm{H}_{4}-\mathrm{La}\right)^{3+}\right]-\mathrm{C}_{60}+3 \mathrm{acac}^{-}\right\}^{6+}(\mathrm{m} / z$ 572) were detected (Fig. 12a). Similar to ${ }^{14} \mathrm{~N}_{2}-\mathrm{H}_{4}$-La, doubly charged ions $(\mathrm{m} / \mathrm{z} 813$ and 815$)$, quadruply charged ions $(\mathrm{m} / \mathrm{z} 633$ and 635), and sextuply charged ions $(m / z 573$ and 575$)$ were detected in the case of ${ }^{15} \mathrm{~N}_{2}-\mathrm{H}_{4}$-La and ${ }^{15} \mathrm{~N}_{2}-\mathrm{D}_{4}-\mathrm{La}$, respectively (Fig. 12b and 12c). The identical isotopic shifts of ca. $\mathrm{m} / z$ 1.0 in ${ }^{15} \mathrm{~N}_{2}-\mathrm{H}_{4}-\mathrm{La}-\mathrm{C}_{60}$ and ca. $m / z 3.0$ in ${ }^{15} \mathrm{~N}_{2}-\mathrm{D}_{4}-\mathrm{La}-\mathrm{C}_{60}$ appearing in the corresponding three different charge states are shown in Table 1. Partially isotope-labeled ions were detected. In the case of doubly charged ions, ${ }^{15} \mathrm{~N}_{2}-\mathrm{H}_{2}-\mathrm{D}_{2}-\mathrm{C}_{60}(\mathrm{~m} / z$ 813.6) and ${ }^{15} \mathrm{~N}_{2}-\mathrm{H}_{1}-\mathrm{D}_{3}-\mathrm{C}_{60}(m / z$ 814.1 $)$ were detected. In quadruply charged ions, ${ }^{15} \mathrm{~N}_{4}-\mathrm{H}_{1}-\mathrm{D}_{7}-\mathrm{C}_{60}\left(\mathrm{~m} / z\right.$ 634.38), ${ }^{15} \mathrm{~N}_{4^{-}}$ $\mathrm{H}_{2}-\mathrm{D}_{6}-\mathrm{C}_{60}\left(m / z\right.$ 634.13), and ${ }^{15} \mathrm{~N}_{4}-\mathrm{H}_{3}-\mathrm{D}_{5}-\mathrm{C}_{60}(\mathrm{~m} / z$ 633.88) were detected. Moreover, in sextuply charged ions, ${ }^{15} \mathrm{~N}_{6}-\mathrm{H}_{1}$ $\mathrm{D}_{11}-\mathrm{C}_{60}(m / z 574.46),{ }^{15} \mathrm{~N}_{6}-\mathrm{H}_{2}-\mathrm{D}_{10}-\mathrm{C}_{60}(m / z 574.29),{ }^{15} \mathrm{~N}_{6}-$ $\mathrm{H}_{3}-\mathrm{D}_{9}-\mathrm{C}_{60}(m / z 574.13)$, and ${ }^{15} \mathrm{~N}_{6}-\mathrm{H}_{4}-\mathrm{D}_{8}-\mathrm{C}_{60}(m / z$ 573.96) were also detected (Table 2).

\section{Conclusions}

An effective and reliable ionization method called ionic probe attachment ionization demonstrated the utility of novel MS probes (NHS-TMpybox, Mal-TMpybox, BrAc-TMpybox, oxime-TMpybox, and Sar-TMpybox) in the ionization of various large complex molecules, including biomolecules and carbon clusters, with CSI-MS. NHS-TMpybox that was reacted with the amino group by simple mixing in acetonitrile clearly produce multiply charged ions of the probe-attached compound $\left(\left[\mathrm{M}^{n+}\right]\right)$ in CSI-MS. TMpybox series could react with correlative molecules under mild conditions and are easily synthesized. In addition, an analyte to which isotope-labeled pybox-La complexes were attached was easily ionized in soft conditions and exhibited reasonable isotopic shifts. We believe that this method is useful for the analysis of proteomes and various isotopes as well as the analysis of large complex molecules by deducing the mass-to-charge ratio from the mass spectrum. This ionization method using these probes was suitable for the soft spray ionization including ESI and CSI. However, MALDI is not recommended because the charged site of the probe easily reacts with matrix. Especially, in the case of large biomolecules, CSI will be the best choice.
In the near future, we foresee that these MS probes will be widely utilized by many MS users under soft ionization conditions, such as CSI.

\section{Acknowledgements}

This work was supported by JST, a Grant-in-Aid for Scientific Research on Regional Innovation Areas "Development of a Nitrogen-15 Separation System Using Non-ferrous Smelting Flow \& Utilization Technology" (20R7006), and the Ministry of Education, Culture, Sports, Science and Technology (MEXT) of Japan in the form of a Grant-in-Aid for Scientific Research on Innovation Areas "Emergence in Chemistry" (20111007).

\section{References}

1) G. Siuzdak, "The Expanding Role of Mass Spectrometry in Biotechnology," MCC Press, San Diego (2003).

2) M. Karas, D. Bachmann, and F. Hillenkamp, Anal. Chem., 57, 2935 (1985)

3) J. B. Fenn, M. Mann, C. K. Meng, S. F. Wong, and C. M. Whithouse, Science, 246, 64 (1989).

4) I. A. Kaltashov and R.R. Abzalimov, J. Am. Soc. Mass Spectrom., 19, 1239 (2008).

5) K. Yamaguchi, J. Mass Spectrom., 38, 473 (2003).

6) A. Honda, H. Komatsu, D. Kato, A. Ueda, K. Maruyama, Y. Iwasaki, T. Ito, O. Niwa, and K. Suzuki, Anal. Sci., 24, 55 (2008).

7) F. Ito, T. Nakamura, S. Yorita, H. Danjo, and K. Yamaguchi, Tetrahedron Lett., 50, 6252 (2009).

8) F. Ito and K. Yamaguchi, Heterocycles, 81, 985 (2010).

9) C. Toniolo, A. Bianco, M. Maggini, G. Scorrano, M. Prato, M. Marastoni, R. Tomatis, S. Spisani, G. Palú, and E. D. Blair, J. Med. Chem., 37, 4558 (1994).

10) F. Ito, S. Ando, M. Iuchi, T. Nakamura, S. Yorita, and K. Yamaguchi, Org. Biomol. Chem., 8, 4408 (2010).

11) F. Ito, S. Ando, M. Iuchi, T. Ukari, M. Takasaki, and K. Yamaguchi, Tetrahedron, 67, 8009 (2011).

12) F. Ito and K. Yamaguchi, Org. Biomol. Chem., 9, 2674 (2011).

13) M. Sawada, Y. Takai, H. Yamada, H. Yamaoka, T. Azuma, T. Fujioka, Y. Kawai, and T. Tanaka, Chem. Commun., 1569 (1998).

14) M. Shizuma, H. Imamura, Y. Takai, H. Yamada, T. Takeda, S. Takahashi, and M. Sawada, Chem. Lett., 29, 1292 (2000).

15) M. Shizuma, Y. Kadoya, Y. Takai, H. Yamada, T. Takeda, R. Arakawa, S. Takahashi, and M. Sawada, J. Org. Chem., 67, 4795 (2002).

16) M. Sawada, Y. Takai, H. Yamada, S. Hirayama, T. Kaneda, T. Tanaka, K. Kamada, T. Mizooku, S. Takeuchi, K. Ueno, K. Hirose, Y. Tobe, and K. Naemura, J. Am. Chem. Soc., 117, 7726 (1995).

17) S. P. Gygi, B. Rist, S. A. Gerber, F. Turecek, M. H. Gelb, and R. Aebersold, Nat. Biotechnol., 17, 994 (1999).

18） P. L. Ross, Y. N. Huang, J. N. Marchese, B. Williamson, K. Parker, S. Hattan, N. Khainovski, S. Pillai, S. Dey, S. Daniels, S. Purkayastha, P. Juhasz, S. Martin, M. Bartlet-Jones, F. He, A. Jacobson, and D. J. Pappin, Mol. Cell. Proteomics, 3, 1154 (2004).

19) T. J. Griffin, S. P. Gygi, B. Rist, and R. Aebersold, Anal. Chem., 73, 978 (2001).

20) S. P. Gygi, B. Rist, T. J. Griffin, J. Eng, and R. Aebersold, J. Proteome Res., 1, 47 (2002).

21) H. Lee, T. J. Griffin, S. P. Gygi, B. Rist, and R. Aebersold, Anal. Chem., 74, 4353 (2002).

22) P. A. Everley, C. E. Bakalarski, J. E. Elias, C. G. Waghorne, S. A. Beausoleil, S. A. Gerber, B. K. Faherty, B. R. Zetter, and S. P. Gygi, J. Proteome Res., 5, 1224 (2006). 
23) S. Matsuoka, B. A. Ballif, A. Smogorzewska, E. R. McDonald III, K. E. Hurov, J. Luo, C. E. Bakalarski, Z. Zhao, N. Solimini, Y. Lerenthal, Y. Shiloh, S. P. Gygi, and S. J. Elledge, Science, 316, 1160 (2007).

24) C. E. Bakalarski, J. E. Elias, J. Villén, W. Haas, S. A. Gerber, and S. P. Gygi, J. Proteome Res., 7, 4756 (2008).

25) F. F. Evans, M. J. Raftery, S. Egan, and S. Kjelleberg, J. Proteome Res., 6, 967 (2007).

26) S. D. Garbis, S.I. Tyritzis, T. Roumeliotis, P. Zerefos, E. G. Giannopoulou, A. Vlahou, S. Kossida, J. Diaz, S. Vourekas, C. Tamvakopoulos, K. Pavlakis, D. Sanoudou, and C.A. Constantinides, J. Proteome Res., 7, 3146 (2008).

27) L. Dayon, N. Turck, S. Kienle, P. Schulz-Knappe, D. F. Hochstrasser, A. Scherl, and J.C. Sanchez, Anal. Chem., 82, 848 (2010).

28） T. Sasaki, A. J. Osgood, J. L. Kiappes, K. F. Kelly, and J. M. Tour,
Org. Lett., 10, 1377 (2008).

29) W. B. Zhang, Y. Tu, R. Ranjan, R. M. V. Horn, S. Leng, J. Wang, M. J. Polce, C. Wesdemiotis, R. P. Quirk, G. R. Newkome, and S. Z. D. Cheng, Macromolecules, 41, 515 (2008).

30) S. W. Hong, D. Y. Kim, J. U. Lee, and W. H. Jo, Macromolecules, 42, 2756 (2009).

31) B. W. Boudouris, F. Molins, D. A. Blank, C.D. Frisbie, and M. A. Hillmyer, Macromolecules, 42, 4118 (2009).

32) J. D. Megiatto, Jr., R. Spencer, and D. I. Schuster, Org. Lett., 11, 4152 (2009).

33) M. Sawamura, K. Kawai, Y. Matsuo, K. Kanie, T. Kato, and E. Nakamura, Nature, 419, 702 (2002).

Keywords: Ionic probe, Cold spray ionization, Isotope labeling, Mass tag 